\title{
Wound infections acquired from a disperser of an unusual strain of Staphylococcus aureus
}

\author{
G. A. J. AYLiffe AND B. J. COLlins \\ From the Medical Research Council Hospital Infection Research Laboratory, \\ Summerfield Hospital, Birmingham
}

SYNOPSIS Seven post-operative wounds were infected with a strain of Staphylococcus aureus, probably acquired from a theatre orderly who suffered from a dry generalized eczema. The orderly was a nasal and heavy skin carrier, and was shown to be a disperser of the epidemic strain. Infection was probably acquired from airborne contamination in the operating theatre, since the orderly did not scrub-up.

The epidemic strain (phage type $80 / 81$ at 1,000 routine test dilution) was sensitive to penicillin and resistant to tetracycline and novobiocin. Neomycin resistance was variable. This strain was found to lose resistance to neomycin when subcultured in the absence of the antibiotic.

Nasal or skin carriers of Staphylococcus aureus in the operating theatre have often been incriminated as sources of post-operative wound infection (e.g., Devenish and Miles, 1939; Blowers, Mason, Wallace, and Walton, 1955; Shooter, Griffiths, Cook, and Williams, 1957; Penikett, Knox, and Liddell, 1958; Browne, Ryan, Glassow, Martin, and Shouldice, 1959). Although the passage of organisms through punctures in gloves may be the major factor, the actual mechanism of transfer from carrier to patient is rarely certain; evidence of infection from unscrubbed persons in the operating room is unusual (Sompolinsky, Hermann, Oeding, and Rippon, 1957; Walter, Kundsin, and Brubaker, 1963; Bassett, Ferguson, Hoffman, Walton, Blowers, and Conn, 1963). In addition to persons with infections or certain skin diseases, some staphylococcal carriers with apparently normal skin release many particles carrying Staph. aureus into the environment (Duguid and Wallace, 1948; Hare and Thomas, 1956; Noble and Davies, 1965; Bethune, Blowers, Parker, and Pask, 1965), and one of these dispersers in the operating theatre would be a special hazard.

The present investigation describes post-operative wound infections probably acquired from a theatre orderly who was a nasal and skin carrier of Staph. aureus. Dispersal of staphylococci into the environment by the carrier was studied in the laboratory. The staphylococcus isolated from the infections and the carrier was an unusual strain showing

Received for publication 20 September 1966. variable resistance to neomycin; other studies were also made in vitro on loss of resistance to neomycin.

\section{DESCRIPTION OF INFECTIONS}

Three post-operative wounds infected with the 'epidemic' strain of Staph. aureus were found in a female surgical ward (B). The first patient with an infected wound (admitted 18 October 1965, discharged 2 November 1965) had an operation for varicose veins, and was discharged six days before the second patient was admitted. The epidemic strain was not isolated from patients, staff, or environment in the ward during the six-day interval. The second patient had a cholecystectomy performed and was discharged on 27 November 1965 , and the third patient was admitted on 22 November 1965 for a mastectomy; these two patients were both in the open section of the ward for five days and ward cross infection cannot be excluded. Operations on all three patients were performed by the same surgical team and in the same theatre, which was not mechanically ventilated. Patients of another surgeon in the ward had operations in a different theatre and were not infected by this strain. Further investigation in other wards of the hospital disclosed that four other post-operative wounds (two herniorrhaphies, a cholecystectomy, and a leg amputation) were infected by the epidemic strain between May and November 1965. These operations were performed by a different surgical team, but in the same theatre as the three infected patients from 
ward $B$. The investigation at this stage suggested a source in the theatre $(C)$ and subsequently one nasal carrier of the neomycin-resistant strain was found on the theatre staff.

\section{METHODS}

WARD INVESTIGATION A detailed epidemiological study of infections, carriers, and environmental contamination was made in ward B from 14 October 1965 when patients were first admitted. The ward consists of one open section with 14 beds and five single-bedded rooms. Two of these rooms are equipped with partial recirculation air conditioners and two with a plenum ventilation system. Nasal swabs were taken daily from all patients and once weekly from members of the staff. Wound swabs were taken daily or, if dressed less frequently, at each time of dressing. Settle plates were exposed for two hours daily on five days each week. Slit-sampling studies were made twice weekly and floor impression plates (Foster, 1960) were taken from the main patient areas.

OPERATING THEATRE INVESTIGATION Nose swabs were taken from the 16 members of the staff of theatre $C$, and settle plates were exposed for two hours during each of two operating sessions.

INVESTIGATION OF STAPHYLOCOCCAL NASAL CARRIER The theatre orderly who carried the epidemic strain in his nose was studied for skin carriage and dispersal. Swabs were taken from the nose, throat, beard area, neck, wrists, chest, axilla, perineum, and behind the knees. Hair and fingers were sampled by direct contact with nutrient agar plates. Slit-sampling studies were made while the subject walked normally around a small laboratory (size approximately 1,000 cu.ft.) for five minutes. Six further experiments were made while the subject removed some of his outer clothing, rubbed his arms, shook his head, and mildly exercised his arms and legs for five minutes in one area of the room near the slit-sampler. Settle plates were exposed $2 \mathrm{ft}$. above the floor during and after the experiment for a period of 30 minutes; impression plates were taken from the floor at the end of this period. In each experiment 125 cu.ft. of air was sampled on nutrient agar plates containing $10 \mu \mathrm{g} . / \mathrm{ml}$. novobiocin. One hundred and twenty-seven of the colonies of Staph. aureus isolated from various sites on the carrier were tested for neomycin and novobiocin sensitivity. Skin swabs were also taken from a nasal carrier of a different neomycin-resistant strain, and a slit-sampling study was made during exercise of this subject.

BACTERIOLOGICAL METHODS Nutrient agar plates containing phenolphthalein diphosphate (Barber and Kuper, 1951) were used for nose and skin swabs, settle plates, slit sampling in the ward, and floor impression plates. Wound swabs were cultured on horse blood agar and on MacConkey agar plates. All plates were incubated for 18 hours and colonies of presumptive Staph. aureus were subcultured on blood agar and subsequently confirmed by tube coagulase tests. Strains of Staph. aureus were tested for sensitivity to a range of antibiotics by a ditch plate method and typed with the routine set of phages supplied by the Central Public Health Laboratory, Colindale (Blair and Williams, 1961).

NEOMYCIN RESISTANCE A neomycin-resistant strain was investigated for loss of resistance to neomycin on repeated subculture and a neomycin-sensitive strain was examined for the presence of resistant variants. Both strains were isolated from the same infected wound and were similar in phage type; the antibiotic resistance patterns differed only in resistance to neomycin.

A single colony of the neomycin-resistant organism was spread on an agar plate; 100 colonies were tested for resistance using ditch plates containing $50 \mu \mathrm{g} . / \mathrm{ml}$. neomycin. This strain and another unrelated neomycinresistant strain were subcultured daily in nutrient broth for 10 days. The broths from the last subculture were spread on agar plates and 100 colonies of each organism were again tested for neomycin resistance. After leaving the broths from the last subculture for two weeks at room temperature, subcultures were spread on agar plates and 30 colonies from each tube of broth were tested for neomycin resistance.

The minimum inhibitory concentration of neomycin for the neomycin-sensitive and resistant strains was estimated by a plate dilution method, and a similar test using a heavy inoculum ( $10^{8}$ organisms) was made to determine the presence of neomycin-resistant mutants in the sensitive strain.

\section{RESULTS}

The strains of Staph. aureus isolated from the seven wounds and the carrier were sensitive to penicillin and resistant to novobiocin and tetracycline; neomycin resistance was variable. The strains were not typable by staphylococcal phages at routine test dilution (R.T.D.) but were lysed by phages $80 / 81$ at 1,000 R.T.D.

WARD INVESTIGATION The epidemic strain was not isolated from the noses of patients with wound infections due to the strain, or from members of the ward or surgical staff. One patient whose wound was not infected acquired the neomycin-resistant strain in the nose two days after the strain was isolated from the wound of the third patient; after two days the strain was no longer present in the nose of this patient. The epidemic strain was isolated from the air of the ward on only two occasions; the first (two colonies on one settle-plate) was in the cubicle of an infected patient and the second (eight colonies in 100 cu.ft. of air) was in the open ward when there were no infections or known carriers of the strain amongst the patients or ward staff. However, the orderly who carried the strain had visited the ward on the same day. 
THEATRE INVESTIGATION The epidemic strain was isolated from the nose of one member of the theatre staff and in small numbers ( $<1$ per plate) from settle-plates exposed during two operating sessions.

INVESTIGATION OF STAPHYLOCOCCAL CARRIER Staph. aureus was isolated in large numbers from the hair, fingers, neck, chest, behind the knees, and in smaller numbers from the nose, throat, wrists, beard area, and perineum but not from the axilla. One hundred and twenty-four out of 127 colonies selected from these sites were resistant to neomycin and all were resistant to novobiocin. One hundred and thirtyfive novobiocin-resistant colonies of Staph. aureus were isolated during slit sampling (125 cu.ft. of air) while the subject walked in a small room for five minutes. The accompanying Table shows the combined results of six experiments obtained from the carrier after removing outer clothing and mildy exercising for five minutes, and from the floor after the experiment. The results indicated that the subject was a heavy skin carrier and disperser of Staph. aureus. A similar experiment with another nasal carrier of a different neomycin-resistant strain showed no colonies of Staph. aureus on the skin or hair, and one colony in $125 \mathrm{cu}$. ft. of air on slitsampling during exercise.

\section{TABLE}

COLONY CCUNTS OF NOVOBIOCIN-RESISTANT STAPH. AUREUS FROM SIX EXPERIMENTS TO SHOW DISPERSAL OF STAPHYLOCOCCI DURING EXERCISE

\begin{tabular}{|c|c|c|c|c|c|}
\hline \multicolumn{2}{|c|}{ Slit Sampling } & \multicolumn{2}{|c|}{ Settle Plates } & \multicolumn{2}{|c|}{$\begin{array}{l}\text { Floor Impression } \\
\text { Plates }\end{array}$} \\
\hline $\begin{array}{l}\text { No. Air } \\
\text { Sampled } \\
\text { (cu. ft.) }\end{array}$ & $\begin{array}{l}\text { Colonies } \\
\text { (per } \\
\text { cu. ft.) }\end{array}$ & $\begin{array}{l}\text { No. of } \\
\text { Plates }\end{array}$ & $\begin{array}{l}\text { Mean } \\
\text { Colony } \\
\text { Count per } \\
\text { Plate }\end{array}$ & $\begin{array}{l}\text { No. of } \\
\text { Plutes }\end{array}$ & $\begin{array}{l}\text { Mean } \\
\text { Colony } \\
\text { Count per } \\
\text { Plate }\end{array}$ \\
\hline 750 & $1 \cdot 38$ & 14 & $7 \cdot 6$ & 16 & $17 \cdot 3$ \\
\hline
\end{tabular}

NEOMYCIN RESISTANCE Before subculturing the neomycin-resistant strain 10 times in nutrient broth one out of 100 colonies was sensitive to neomycin, and after the last subculture four out of 100 colonies were sensitive. After leaving the broth from the tenth subculture for two weeks and spreading on an agar plate, 29 out of 30 colonies were sensitive to neomycin. No neomycin-sensitive colonies were found in the other unrelated neomycin-resistant strain after similar treatment, and no loss in novobiocin resistance was found in the epidemic strain. Neomycin-resistant variants (minimum inhibitory concentration 8-16 $\mu \mathrm{g} . / \mathrm{ml}$.) were obtained from the neomycin-sensitive strain, but the degree of resistance was much lower than in the naturally occurring neomycin-resistant strains (minimum inhibitory concentration $128 \mu \mathrm{g} / \mathrm{ml}$.).

\section{DISCUSSION}

During a detailed epidemiological study in a female surgical ward, three post-operative wound infections due to an unusual strain of Staph. aureus were found. No source was found in the ward and environmental contamination was minimal. In addition to these three infections, four patients in other wards were found to have wounds infected with a similar organism. Three of the seven infections were almost certainly acquired in the theatre, and the other four could have been acquired either in the ward or the theatre. Since three wards, two surgical teams, and one operating theatre were involved, it was considered that the common source was almost certainly in the theatre. A nasal carrier was found in this theatre and further investigation showed that he was a heavy skin-carrier and disperser of the epidemic strain. No further post-operative infections due to this organism have occurred in the six months since his removal from the theatre. As his duties did not involve scrubbing-up it seemed probable that the infections were due to airborne transfer either directly to the patient or indirectly from contamination of sterile equipment. He was present in the theatre at most of the operating sessions, yet only four out of the 251 wounds were infected with this strain between October and December 1965. The number of infections is surprisingly low, and might easily have escaped attention if the infecting strain had been less characteristic or associated with widespread cross-infection in the hospital wards. However, Walter et al. (1963) also reported a low incidence of wound infection (two out of 169 operations) acquired from a disperser in a theatre. It is also possible that the number of infections might have been further reduced in a mechanically ventilated theatre.

The carrier suffered from a mild generalized dry eczema, and had been treated with a cream containing a steroid and neomycin. Subsequently he used bar soap containing $2 \%$ hexachlorophane for all ablutions and $0.5 \%$ hibitane nose cream three times a day. This treatment failed to eradicate the organism from nose or skin and hexachlorophane baths and liquid soap were tried and discontinued after several days, owing to skin irritation. It seems probable that the eczema would have to be cleared before the organism could be eradicated by antiseptic treatment.

The staphylococci from the carrier were mainly resistant to neomycin (124 out of 127 colonies 
tested) whereas only four out of 15 colonies randomly selected from cultures of wounds from the three patients in ward B carrying this type of staphylococcus were resistant. This suggests that neomycin resistance of the epidemic strain was gradually lost in the absence of the antibiotic and was confirmed by the laboratory studies. However, the other neomycin-resistant strain tested showed no loss in resistance to neomycin in similar tests, resembling in this respect strains described in another study (Lowbury, Babb, Brown, and Collins, 1964).

Further studies on the mechanism of variable neomycin resistance in these organisms are in progress.

We wish to thank Dr. E. J. L. Lowbury for his advice, Mr. L. W. Aldridge, Senior surgeon, and the nursing staff of Dudley Road Hospital for their cooperation, and Miss S. Louis for technical assistance.

\section{REFERENCES}

Barber, M., and Kuper, S. W. A. (1951). J. Path. Bact., 63, 65. Bassett, H. F. M., Ferguson, W. G., Hoffman, E., Walton, M., Blowers, R., and Conn, C. A. (1963). J. Hyg. (Lond.), 61, 83.

Bethune, D. W., Blowers, R., Parker, M., and Pask, E. A. (1965) Lancet, 1, 480.

Blair, J. E., and Williams, R. E. O. (1961). Bull. Wld Hlth Org., 24, 771. Blowers, R., Mason, G. A., Wallace, K. R., and Walton, M. (1955). Lancet, 2, 786.

Browne, A. F., Ryan, E. A., Glassow, F. J., Martin, C. J., and Shouldice, E. E. (1959). J. Amer. med. Ass., 170, 1274.

Devenish, E. A., and Miles, A. A. (1939). Lancet, 1, 1088.

Duguid, J. P., and Wallace, A. T. (1948). Ibid., 2, 845.

Foster, W. D. (1960). Ibid., 1, 670.

Hare, R., and Thomas, C. G. A. (1956). Brit. med. J., 2, 840.

Lowbury, E. J. L., Babb, J. R., Brown, V. I., and Collins, B. J. (1964). J. Hyg. (Lond.), 62, 221.

Noble, W. C., and Davies, R. R. (1965). J. clin. Path., 18, 16

Penikett, E. J. K., Knox, R., and Liddell, J. (1958), Brit. med. J., 1, 812.

Shooter, R. A., Griffiths, J. D., Cook, J., and Williams, R. E. O. (1957) Ibid., 1, 433.

Sompolinsky, D., Hermann, Z., Oeding, P., and Rippon, J. E. (1957). J. infect. Dis., 100, 1 .

Walter, C. W., Kundsin, R. B., and Brubaker, M. M. (1963). J. Amer. med. Ass., 186, 908.

\section{A.C.P. Symposium on the Thyroid Contents}

Editor's Foreword

Chairman's Introduction

The structure of the thyroid gland I. DONIACH

The biosynthesis of thyroid hormones R. PITT-RIVERS

Action of thyroid hormones J. R. TATA

The control of thyroid secretion $\mathrm{K}$. BROWN-GRANT

The radioimmunoassay of thyroid-stimulating hormone in human blood TH. LEMARCHAND-BERAUD

Carriage of circulating thyroid hormones and the estimation of total plasma hormone levels C. OSORIO

Estimation of hormone-binding by plasma proteins, and of unbound levels of thyroxine in plasma F. CLARK

The value of inorganic iodine studies in the clinical assessment of thyroid disease SIR EDWARD WAYNE
Stimulation and suppression tests of thyroid function R. I. S. BAYLISS

Tests based on the peripheral action of thyroid hormone R. HALL

Aetiology of hyperthyroidism DONALD S. MUNRO

Diagnosis of hyperthyroidism J. CROOKS

Hypothyroidism A. STUART MASON

Hypothyroidism due to congenital dyshormonogenesis E. M. MCGIRR

Autoimmune disease of the thyroid DEBORAH DONIACH

Extra thyroid or thyroglobulin I. M. ROITT

Medullary carcinoma of the thyroid E. D. WILLIAMS

Thyrocalcitonin I. MCINTYRE 